\title{
CURCUMIN - THE HEALING HERB: PROPERTIES AND FUTURE PROSPECTIVE
}

\author{
GAURAV SHARMA, NITIKA THAKUR*
}

Microbiology Research Laboratory, Faculty of Applied Sciences and Biotechnology, Shoolini University, Solan, Himachal Pradesh, India. Email: nitikathakur45@gmail.com

Received: 03 August 2018, Revised and Accepted: 12 December 2019

ABSTRACT

Curcumin, the main bioactive compound found in turmeric rhizomes, has a wide variety of applications in the clinical field that is why it attracts researchers from all over the world. While there are various studies on curcumin extraction and quantification, comparison of curcumin content according to the soil profile and cultivation period has not been performed yet in our knowledge. Curcumin to be a genuine natural product having impressive anti-oxidant and anti-inflammatory properties, treating a wide range of diseases. Curcumin is a special gift to humans given by mothernature to help them curing many diseases. Turmeric, the plant containing a significant amount of this molecule, has been used for many centuries as a traditional medicine to cure skin problems, digestive issues, as painkiller, and much more. From the past two centuries, scientists found many applications of this molecule in the clinical field. There are still many properties of this wonder drug that need to be discovered. However, the obstacle in this track is difficulty in extracting the pure and high amounts of curcumin from turmeric rhizomes. For this reason, many researchers have searched about many techniques to extract curcumin from turmeric rhizomes, of which ultra-high-performance liquid chromatography-mass spectrometry has been found very efficient. The review will assist the researchers to discover and choose the plant to develop adequate medicine for establishing costeffective treatments.

Keywords: Turmeric, Curcumin, Anti-oxidants, Anti-inflammatory.

(C) 2020 The Authors. Published by Innovare Academic Sciences Pvt Ltd. This is an open access article under the CC BY license (http://creativecommons. org/licenses/by/4. 0/) DOI: http://dx.doi.org/10.22159/ajpcr.2020.v13i2.28929

\section{INTRODUCTION}

Turmeric (Curcuma longa) is the traditional yellow-colored root belonging to the family of ginger, Zingiberaceae. It is an ancient spice and a native of South East Asia, a perennial herbaceous plant requires the temperature between 20 and $30^{\circ} \mathrm{C}$. C. longa is a spice native to India. Historically, turmeric has been used throughout India, China, and Indonesia as a spice and medicinal agent. India is the largest producer of turmeric in the world ( $93.7 \%$ of the total world production) and is cultivated in 150,000 ha in India [1]. Curcuma zedoaria Rosc, also known as white turmeric, zedoaria or gajutsu [2], is a perennial rhizomatous herb that belongs to the Zingiberaceae family. The plant is indigenous to Bangladesh, Sri Lanka, and India, and is also widely cultivated in China, Japan, Brazil, Nepal, and Thailand. In India, it is known by its several vernacular names, the most commonly used ones being Krachura (Sanskrit), Gandamatsi (Hindi), and Sutha (Bengali) [3]. It is used traditionally for the treatment of menstrual disorders, dyspepsia, vomiting [4], and for cancer. The rhizome of Curcuma aromatica is also used in medicines as a stomachic, carminative for skin diseases, and recently as a health food in Japan [5]. Phytoconstituents in turmeric are diferuloylmethane and many volatile oils including atlantone. In Ayurveda, it is extensively used for a long time having no side effects and has different medicinal properties which include analgesic, antiinflammatory, antioxidant, antiseptic, and anticarcinogenic activity [6]. In another study, it was detected that curcumin can cure different precancerous situations such as oral submucous fibrosis, lichen planus, and leukoplakia. The oil from turmeric possessed oncopreventive activity [7] and cure numerous oral diseases. Application of roasted, ground turmeric reduces the pain and swelling [6]. Another study concluded that turmeric solution can greatly reduce the gum inflammation than chlorhexidine [8]. The oil from turmeric possesses oncopreventive activity, cures numerous oral diseases, and reduces gum inflammation [7]. India has a rich history of using plants for medicinal purposes. Turmeric (C. longa L.) is a medicinal plant widely used in Ayurveda, Unani, and Siddha medicine as a home remedy for various diseases $[9,10]$. Haridara as we refer to turmeric in ancient India Vedic texts has been used continuously for their coloring, flavoring, and digestive properties and gained further importance when Ayurveda, the ancient medical practice from India, it has been systematized by Caraca and Susruta [3,11]. Turmeric is still there widely used as a versatile spice throughout India, the Middle East, and the Far East, both in vegetarian and non-vegetarian food preparations. It also has a traditionally important place in feminine cosmetics for its bright yellow color and its characteristics fresh scent even the same bright yellow color seems to have been chosen for religious and auspicious occasions [12]. These uses and practices continue in India and in Southeast Asia, even today.

\section{Taxonomy:}

Kingdom: Plantae

Division: Magnoliophyta

Class: Liliopsida

Order: Zingiberales

Family: Zingiberaceae

Genus: Curcuma

Species: longa

Various names [13]

\begin{tabular}{ll}
\hline Language & Name \\
\hline Arabic & Kurkum, Uqdah safra \\
Armenian & Toormerik, Turmerig \\
Assamese & Halodhi \\
Bengali & Halud \\
Bulgarian & Kurkuma \\
Burmese & Hsanwen, Sanwin, Sanae, Nanwin \\
Catalan & Cúrcuma \\
Chinese & Yu chin, Yu jin, Wohng geung, Geung wohng, Wat gam, \\
& Huang jiang, Jiang huang, Yu jin, Yu jin xiang gen \\
Croatian & Indijski šafran, Kurkuma \\
\hline
\end{tabular}

Chemical composition of turmeric

Turmeric contains proteins (6.3\%), fats (5.1\%), minerals (3.5\%), carbohydrates (69.4\%), and humidity (13.1\%). The essential oil (5.8\%) obtained by steam distillation of rhizomes has $\alpha$-phellandrene $(1 \%)$, 
sabina $(0.6 \%)$, cineol $(1 \%)$, borneol $(0.5 \%)$, zingiberene $(25 \%)$, and sesquiterpine (53\%) [14]. Curcumin (diferuloylmethane) (3-4\%) is responsible for the color yellow and includes curcumin I (94\%), curcumin II (6\%), and curcumin III (0.3\%) [15]. Demethoxy and also the bis-methoxy curcumin derivatives have isolated state [16]. Curcumin was isolated for the first time [17] 1815 and its chemical structure was determined by Roughley and Whiting [18] in 1973. It has a melting point at $176-177^{\circ} \mathrm{C}$; it forms a reddish-brown salt with alkali and is soluble in ethanol, alkali, ketone, acetic acid, and chloroform.

In patients undergoing surgery, the oral application of curcumin reduces post-operative inflammation [19]. Recently, curcumin has been formulated as a slow biodegradable version microsphere for the treatment of inflammation in arthritis rats [20]. It is evident from the study that curcumin biodegradable microspheres could be used successfully for the therapeutic management of inflammation [20].

\section{Evaluation of safety with turmeric and curcumin}

Detailed studies on safety assessment have been reported of the rhizomes of $C$. longa and its alcoholic extract, curcumin [21,22].

Curcumin was given to Wistar rats, guinea pigs, and monkeys of both sexes at a dose of $300 \mathrm{mg} / \mathrm{kg}$ body weight, no pathological, behavioral, or lethal anomalies were observed [23]. No adverse effects were observed in either growth or level of erythrocytes, leukocytes, and blood components such as hemoglobin, total serum proteins, and alkaline phosphatase. Human clinical investigations also indicate that curcumin has no toxicity when administered in doses of $1-8 \mathrm{~g} /$ day [24] and $10 \mathrm{~g} /$ day [25].

\section{Curcumin}

Curcumin, a gift from Mother Nature to humans, is nearly 2 centuries old in scientific history, and it is still the center of attraction of researchers from all over the world. With curcumin, oleoresin oil, and other complex compounds, it is lately gaining importance as the potential source of drugs for various ailments. Turmeric oil is used as aromatherapy and in the perfume industry apart from religious, cultural uses [26]. This pigment from turmeric is one of the very few auspicious natural products that have been broadly investigated by researchers from both the chemical and biological point of view [27]. Herbal oral rinses which contain Yavani satva, Bibhitaka (Terminalia bellirica), and Peppermint satva are effective toward gingivitis. As compared to chlorhexidine, the usage of herbal oral rinses such as neem, turmeric showed a higher decrease in biofilm, inflammation of gums, and gum bleeding. The anticancer activity of these plants was associated with their components of major types of phenolic compounds such as phenolic acids, flavonoids, tannins, lignans, quinones, coumarins, curcuminoids, and stilbenes [28]. Curcumin was found to be capable of decreasing the complications of diabetes mellitus [29]. The chemistry of curcumin, an asymmetric molecule of turmeric, is highly stable in natural form. Its intense yellow color changes to deep red in the solution of basic $\mathrm{pH}$. This molecule is susceptible to fast degradation in simple aqueous and aqueous-organic solutions and also on exposure to sunlight. Their study also concluded that the metabolic products of curcumin are different from the degradation products and are difficult for synthesis in the laboratories [30].

Curcumin is the principal curcuminoid of the turmeric; it is a main active constituent. Curcumin has been found to possess anticancer activities through its effect on a variety of biological pathways involved in mutagenesis, oncogene expression, cell cycle regulation, apoptosis, tumorigenesis, and metastasis. Curcumin has shown anti-proliferative effect in multiple cancers, and is an inhibitor of the transcription factor nuclear factor kappa-B (NF-KB) and downstream gene products including c-myc, Bcl-2, cyclooxygenase-2 [COX-2], nitric oxide synthase [NOS], cyclin D1, tumor necrosis factor- $\alpha$ [TNF- $\alpha$ ], interleukins [ILs], and matrix metalloproteinase-9 [MMP-9]). In addition, curcumin affects a variety of growth factor receptors and cell adhesion molecules involved in tumor growth, angiogenesis, and metastasis [31]. Curcumin activates the DNA damage response, providing an opportunity and rationale for the clinical application of these nutraceuticals in the chemoprevention of prostate cancer [32]. Shiri et al. confirmed that the combination of Curcumin and Berberine synergistically generates anticancer effects in A549, Hep-G2, MCF-7, Jurkat, and K562 cells in vitro, possibly mediated by inducing apoptosis. With regard to A549, Hep-G2, MCF-7, Jurkat, and K562 Curcumin and Berberine are of extreme antitumor agents [33]. Rajakrishnan et al. study shows that curcumin asserts its antitumor activity in cancer cells by altering the deregulated cell cycle through (a) cyclin-dependent, (b) p53-dependent, and (c) p53-independent pathways. Such influences of curcumin on key signal transduction pathways of cell cycle and effectiveness in animal model systems have qualified it as a multiple edged sword in combating the deadly disease-cancer [34]. Curcumin is well tolerated in humans. Therefore, EGFR-miRNA-autophagy and cancer stem cell-based therapy in the presence of curcumin might be promising mechanisms and targets in the therapeutic strategy of lung cancer [35]. Nisar et al. study indicates the protective effects of a dendrosomal curcumin formulation on mice metastatic breast cancer, witnessed by increase in representation of M1 macrophages (confirmed by upregulation of STAT4 and IL-12), and decrease in M2 macrophages (confirmed by downregulation of STAT3 IL-10 and arginase I) in a typical animal model of metastatic breast cancer [36]. Curcumin passes the blood-brain barrier. Curcumin was shown to be neuroprotective against ethanol-induced brain injury in vivo following oral administration; an effect that was related to a reduction in lipid peroxide levels and enhancement of glutathione in rat brain [37]. Curcumin protects the brain against damage caused by alcohol consumption, whereby a decrease in oxidative stress and lipid peroxidation (LOP) and an improvement of the glutathione level in brain tissue are seen. In healthy volunteers, a low oral dose of curcumin $(20 \mathrm{mg} /$ day for 75 days) resulted in a significant fall in serum LPO by $60 \%$ [38]. Curcumin is a bioactive natural phytochemical compound rich in phenol (diferuloylmethane) found as abundant in the rhizome of the turmeric plant. It is belonging to the family Zingiberaceae [39]. Curcumin possesses numerous health benefits and is highly effective to treat various diseases, including anorexia, coryza, cough, hepatic diseases, and sinusitis. Curcumin has potential prophylactic, and therapeutic use, as antifungal, anticarcinogenic, antiviral, antimutagen, anti-infectious, antiparasitic, anti-inflammatory, and antioxidant compound. The neuroprotective effects have been observed from curcumin and are effective to treat age-related neurodegenerative diseases. Many studies revealed that Cur exhibits various antioxidant properties. In general, commercially available curcumin contains approximately $3 \%$ bisdemethoxycurcumin, $17 \%$ dedesmethoxycurcumin, and $77 \%$ curcumin [39]. IPM packages consist of a well-planned and well-executed management practice including pest monitoring, survey, and field scouting to monitor every developmental stage of a pest and to develop an effective strategy. On the whole, these practices not only will minimize the ill effects of chemicals but will also prove a boost for the farmers, researchers and litchi growers to choose eco-friendly methods of management [40]. Another study regarding organic farming concluded that by adopting appropriate organic production technologies productivity levels comparable to those under conventional practices can be achieved in tomato with better quality produce, improved soil health, and nutrient status [41].

Some researchers found curcumin to be a genuine natural product having impressive antioxidant and anti-inflammatory properties, treating a wide range of diseases. The authors stated that the antioxidant property is due to the presence of different functional groups in its structure, including methoxy, phenoxy, and carbon-carbon double bonds. The research over turmeric samples from different geographical regions to quantify and compare the curcumin content. They found out that the curcumin content varies from sample to sample along with quality, which is influenced by various other factors such as season, the variation of soil, and geographical variation. According to the research turmeric of Assam which is also known as Lakadong and Megha Turmeric-1 is known for its superb quality which is mostly produced in Jaintia Hills having high curcumin content [42]. 


\section{EXTRACTION METHODS FOR CURCUMIN}

Gas chromatography-mass spectrometry (GC-MS) method was used for the extraction of curcuminoids from dyes of turmeric samples. Two solvents were used as extracting solvents: Methanol and acetone (Ahn et al., 2005). Some reported the development of the GC-MS method for the identification of polar metabolites from the methanolic extract of Curcuma domestica [43]. An efficient, precise, and sensitive highperformance thin-layer chromatography (HPTLC) was developed for the determination of curcumin. They studied this method over several marketed turmeric samples to compare with in-house samples. Dichloromethane and methanol were used as the mobile phase and the HPTLC plate of $0.2 \mathrm{~mm}$ layer thickness was used. They concluded that a lesser amount of curcumin was present in a marketed sample than the in-house sample of turmeric powder. They stated that this proposed method is reliable, accurate, and sensitive for the quantitative estimation of curcumin [44]. Protein misfolding and their accumulation inside or outside of neurons are the key pathological feature in several neurodegenerative diseases, including Alzheimer's, and Parkinson's Huntington's disease. Herbal medicines are regarded as effective and promising sources of potential neuroprotective agents because of their cognitive benefits and more significantly, their mechanisms of action with respect to the fundamental pathophysiology of the diseases [45]. HPTLC method was developed using the combination of three solvents as a mobile phase, i.e., toluene-chloroform-methanol $(5: 4: 1, \mathrm{v} / \mathrm{v} / \mathrm{v})$. The aim of their research was to quantify the variability in the content of curcumin in $C$. longa collected from different geographical regions of India using the HPTLC analysis method. From the eight samples of eight states Guwahati (Assam), Nasik (Maharashtra), Patna (Bihar), Delhi, Trivandrum (Kerala), Lucknow (Uttar Pradesh), Surat (Gujarat) and Erode (Tamil Nadu)], and Erode's (Tamil Nadu), turmeric sample was found with maximum percentage of curcumin present in it whereas Surat (Gujarat) with the lowest percentage. According to the authors, this method was simple, precise, accurate, time saving, cost effective, and specific [46]. Tracy et al., while developing a high-performance liquid chromatography (HPLC) method, used two columns, a C18 and the Accucore Polar Premium and two solvents, methanol and acetonitrile were used for comparison. Solid C18 HPLC column along with Polar embedded columns were generally used for analysis of curcuminoids providing satisfactory results. Results showed that Accucore Polar Premium resolved major and minor curcuminoids completely, whereas the C189 column could only provide partial resolution. They concluded that column selectivity also affects resulting data [47]. Curcumin decreases histone and protein acetylation, increases histone acetylation, and reduces expression of several histone deacetylases sequences-specific demethylation at promoter regions of epigenetically silenced genes [48].

Ashraf et al. repeated the previously performed research using ultra-high-performance liquid chromatography (UPLC) to determine curcuminoids in turmeric sample of eight different states of India (Guwahati [Assam], Nasik [Maharashtra], Patna [Bihar], Delhi, Trivandrum [Kerala], Lucknow [Uttar Pradesh], Surat [Gujarat], and Erode [Tamil Nadu]). The UPLC-tandem MS (UPLC/Q-TOF-MS) was developed and validated for the curcuminoid quantification with the aim to reduce analysis time and enhance efficiency. The research concluded UPLC method to be the reliable, sensitive, and specific technique for the analysis of basic drugs [49]. Geethanjali et al. collected turmeric samples from nine states of India and analyzed those turmeric samples for curcumin content using ultraviolet-visible (UV) spectrophotometry. They found that geographical variation and other factors such as soil, climate, rainfall, and method of cultivation drastically affect the content of curcumin in turmeric samples. Out of nine states (Kerala, Karnataka, Maharashtra, Manipur, Tamil Nadu, Uttar Pradesh, Kolkata, Andhra Pradesh [AP], and Odisha), turmeric samples from Odisha and AP revealed with maximum curcumin content. They concluded by their research that the UV method offers the simplistic method of the estimation of curcumin content compared to other expensive chromatographic methods [50].
A method was developed for the separation of curcuminoids from turmeric sample using an Agilent 1290 Infinity LC and sub-2 $\mu \mathrm{m}$ (STM) column instead of traditional United States Pharmacopeia method. In this experiment, they showed that when Agilent 1290 Infinity LC system is coupled with an STM column then the time is reduced for separating complex botanical extracts and less solvent and labor is used. This method proved to provide good resolution with rapid cycle times [51]. Kulkarni et al. used the combination of methods for the extraction and purification of curcuminoids from turmeric samples. Soxhlet extraction method used to extract curcumin using chloroform, ethyl acetate, methanol, and acetone as their solvents and then the estimation of curcuminoids done by the spectrophotometric method [52]. Purification of the curcuminoids obtained was performed using column chromatography and run on TLC. They concluded methanol as the best extracting solvent used for curcumin extraction using these methods [53]. Popuri et al. extracted curcumin from turmeric roots using the HPLC technique with different solvents to determine the extraction weight of different solvents for curcumin and optimum parameters which give the high yield. Optimum parameters applied were feed size, temperature, solid to solvent ratio, time, and solvents. Out of different solvents used (acetone, ethyl acetate, ethanol, methanol, isopropanol, and hexane), acetone exhibited good yield of curcumin so they concluded that out of six solvents used, only acetone was able to extract curcumin up to satisfactory resolution and an optimum solvent for curcumin extraction from turmeric samples [54].

\section{APPLICATIONS OF CURCUMIN}

Sareen et al. developed and optimized curcumin loaded microsponges for colon targeting in inflammatory bowel disease. They studied the curcumin for colon-specific drug delivery system for enhanced therapeutic effects [55]. The microsponges loaded by curcumin were successfully developed in this research using a quasi-emulsion technique for colon targeting. In this research, they concluded that curcumin loaded microsponges could be considered as a promising drug delivery system for treating ulcerative colitis. They defined it as a boon for colonic diseases [56]. Naama et al. studied the anticancer activities of ethanolic curcumin extract by column chromatography, UVvisible, proton nuclear magnetic resonance spectroscopy, and Fouriertransform infrared as the extraction methods [57]. They studied the antioxidant activities of ethanolic curcumin by donating hydrogen to free radicals in its reduction to unreactive species. The hydrogen-donating activity was measured using 1, 1-diphenyl-2-picrilhydrazyl radicals which act as hydrogen acceptors and showed that there was a significant association between the concentration of extract and percentage of inhibition [58]. Furthermore, in this study, the curcumin and ethanolic extracts were evaluated for preliminary estimation of in vitro tumor inhibition activities against a cell line of human hepatocellular liver carcinoma [59]. Results of this study revealed that the ethanolic curcumin extract shows some correlations between antitumor activity and the structures; in this the dioxo moiety on the curcumin may play an important role in the inhibition of tumor cell line. On the basis of results reported by the studied the authors concluded that pure curcumin and the crude ethanolic extract have great potential in the prevention and cure of cancer [60]. In Alzheimer's disease, it has been shown that curcumin has the ability to bind $A \beta$ peptides, prevent aggregation of new amyloid deposits and promote disaggregation of existing amyloid deposits [61]. Scientific studies also reported that curcumin and its analogs demethoxycurcumin and bis-demethoxycurcumin can protect cells from $A \beta$-induced oxidative stress [62]. Curcumin has the ability to inhibit $A \beta$ oligomerization and fibril formation, enhances $A \beta$ uptake by macrophages, and inhibits the peroxidase activity of A beta-heme complex [63]. Curcuminoid is a polyphenolic compound from turmeric attenuated mitochondrial dysfunction which is induced by oxidative stress and inflammatory responses to inflammatory cytokines, COX2 , and iNOS. Curcuminoids also bind to $A \beta$ plaques to inhibit amyloid accumulation and aggregation in the brain [64,25]. 
Aggarwal et al. researched over the potential of curcumin as the therapeutic agent against a wide range of diseases such as cancer, lung diseases, autoimmune diseases, neurological diseases, liver diseases, metabolic diseases, cardiovascular diseases, and various other inflammatory diseases [65]. Some of the common disease targets of curcumin are shown in Fig. 1. Aggarwal et al. also confirmed that curcumin acts at several stages of cancer development. Aggarwal and his associates had concluded that curcumin blocks transformation, tumor initiation, tumor promotion, invasion, angiogenesis, and metastasis. According to in vitro and animal studies, they revealed that curcumin suppresses carcinogenesis and inhibits the proliferation of a wide variety of tumor cells. Another study reveals that curcumin has been shown to have anti-rheumatic and anti-arthritic effects, most likely through

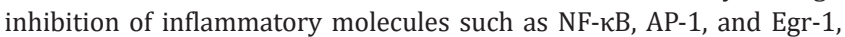
COX2, LOX, NOS, MMP-9, uPA, TNF, and chemokines. In studies conducted during year 2004, curcumin studies revealed that it is effective against atherosclerosis and myocardial infarction by inhibiting proliferation of peripheral blood mononuclear cells and vascular smooth muscle cells, which are the hallmark of atherosclerosis. Reports by various other researches by the same team suggest that curcumin accelerates wound healing and in addition, it also prevents the formation of scars and plays a role in muscle regeneration after trauma [66].

Prasad et al. reviewed many research papers about history, chemistry, and mechanism of action of curcumin and concluded that curcumin is a highly promiscuous natural product. Their studies made it clear that a simple component of nature can interact with multiple molecular targets involved in a wide variety of diseases. According to the research paper, they reviewed that curcumin is of great therapeutic value on the clinical basis to humans and animals. For the future prospective curcumin meets most of the criteria for drug development, i.e., Safety, efficacy, and affordability [69]. Sajithlal et al. reviewed the research papers and the researchers conducted over the new mechanisms and the antiinflammatory role of curcumin in obesity and obesity-related metabolic diseases and concluded curcumin has potential complementary effects on obesity and inflammatory diseases [27]. These mechanisms include suppression of inflammatory proteins, uptake of glucose, stimulation of catabolic pathways in adipose tissues, liver and other tissues, inhibition of angiogenesis in adipose tissue, inhibition of differentiation of adipocytes, stimulation of apoptosis of mature adipocytes, and reduction in chronic inflammation associated with adiposity [70]. They aimed to study the modulation of transcription factors by curcumin. They proved that a number of transcription factors are strongly affected by the activity of curcumin, including NF-kB, AP-1, p53, Egr-1, STAT-3, AR, and AR-related cofactors whose overexpression or constitutive expression in a cell leads to a diseased condition [71]. This was possible because of the versatile chemical structure of curcumin which enables the molecule to interact with a large number of molecules inside of the cell, leading to a variety of biological effects, for example, modulation of cell cycle suppression of growth, induction of differentiation, upregulation of proapoptotic factors, and inhibition of reactive oxygen species production [72]. Their research over the cancer chemopreventive effects of curcumin which lead to the conclusion that curcumin has exhibited chemopreventive

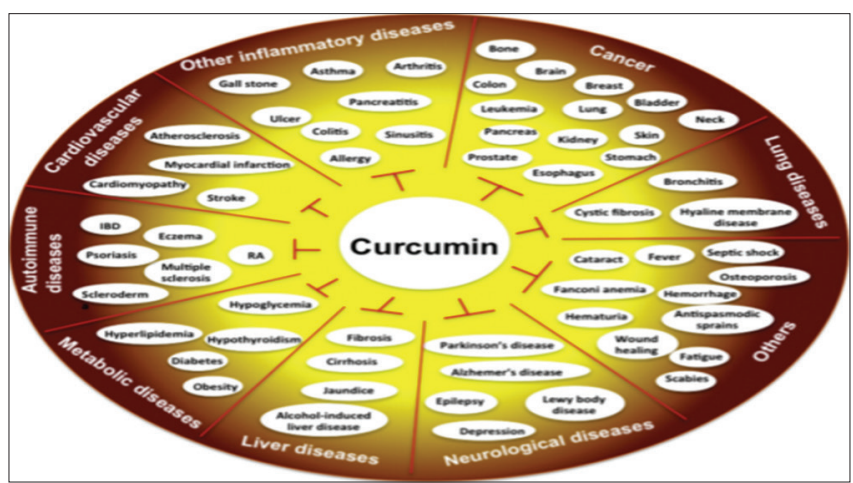

Fig. 1: Diseases targeted by curcumin $[67,68]$ and other health beneficial benefits [73]. They found that curcumin works through multiple underlying molecular mechanisms targeting all stages of multistep carcinogenesis. According to the authors, it will be important to determine whether curcumin will be more effective in humans as an individual agent or as part of the foodstuffs from which it was derived [67]. They aimed to study the antitumor, anti-invasion, and anti-metastatic effects of curcumin, where they found out that curcumin shows cytotoxic potential against tumor cells in both in vitro and in vivo. They concluded that curcumin acts as a good immunomodulator [74]. The mechanism of cytotoxicity of curcumin was found to be the induction of apoptosis, where it either activates or represses several signaling events required for the normal functioning of cells. Curcumin modulates the signaling pathways in such a manner that the final events lead to the death of the cell [75]. They studied angiogenesis (formation of new blood vessels from host vasculature, critical for tumor growth, and metastasis) and curcumin as an inhibitor of angiogenesis where they found out that curcumin is a direct inhibitor of angiogenesis and it also downregulates various proangiogenic proteins such as vascular endothelial growth factors and basic fibroblast growth factors [76]. They concluded that the antiangiogenic effect of curcumin is due to its inhibitory effect on signal transduction pathways and on two groups of proteinases involved in angiogenesis including the fact that the molecules performing cell adhesion are upregulated in active angiogenesis and curcumin can block this effect, adding further dimensions to curcumin's antiangiogenic effect. These studies suggest curcumin's potential as an antiangiogenic drug [30]. Miriyala et al. researched the topic of cardioprotective effects of curcumin in different animal models to show the protective role of curcumin. They found that oxygen free radicals exacerbate cardiac damage and that curcumin induces cardioprotective effects and it also inhibits the free-radical generation in myocardial ischemia studied in rats [77]. This study focused on the mechanistic role of curcumin in vitro, showing anti-platelet and anticoagulant effects [31].

\section{FUTURE PROSPECTIVE OF CURCUMIN}

As in recent decades, health-care cost has been increased and so has increased the importance of naturally occurring phytochemicals in plants for the prevention and treatment of human diseases [70]. Various studies and researches have been undertaken to unfold the role of curcumin in treating many diseases and also to gain insights into curcumin mechanisms at a clinical level and assess, within a short period, the potential success or failure of long-term interventions. According to the review paper of Abu-Taweel et al. [78], futures perspective of curcumin are:

- To increase the bioavailability of curcumin using new formulations based on biocompatible organic substances such as liposomes, polyethylene glycols, biopolymers, cellulose, corn oil, and hydrogels

- The aim of improving the anticancer activity of curcumin by preparing formulations in which the curcumin is bound to novel metal and oxide nanoparticles for easy manipulation for improved delivery, activity, and specificity

- Human clinical trials for clinical applications of curcumin as an anti-inflammatory agent, non-toxic agent for treating skin diseases, anti-tumor agent, cardioprotective molecule, etc., and much more

- For future prospects of curcumin to be performed, high quality of curcumin is necessary with easy and cost-effective extraction methods to make curcumin easily available. Furthermore, cultivation methods, climatic conditions, and quality of soil affect the quality of curcumin. I have undertaken this research to find out about soil quality and curcumin content of turmeric samples of Himachal Pradesh's three districts out of five major producing areas [79].

\section{CONCLUSION}

Turmeric is one of the most precious and powerful plants on earth and is being used as a natural wonder by the ancient people of India. Turmeric is proving beneficial in the treatment of many different health conditions from cancer to Alzheimer's disease. According to a study on plant nutrition affecting turmeric production and curcuminoids yield, low or moderate amount of NPK with soil pH 5-7 is optimum 
and provides a high amount of curcuminoids and volatile oil [80]. Herbal plants are very rich sources of phytochemicals and other active constituents which are responsible for increasing nootropic activity [81].

The Shelf life of tomato sauce grown organically was reported to increase as compared to conventional one [82]. In silico approaches generally highlight an insight to the use of signature sequences (promoter elements) and other related flanking elements. Agricultural sector mainly organic sector needs to be linked with modern techniques which can elevate its level and provides a clear explanation about the drawbacks and sources of improvement [83]. Agricultural sustainability and competitiveness of organic markets are the interlinked areas which jointly needs a serious makeover [84]. The toxic and carcinogenic impacts of synthetic pigments have raised a considerable interest towards a safe alternative highlighting the use of natural pigments, which offers great prospects of natural character, safety, and non toxic and gives spectacular yields [85]. The herbal eye drop (Itone) and the chemical eye drop (Tobastar) are effective against bacterial infections. The components such as neem, tulsi, kapur, and honey in herbal composition possess good antibacterial activity confirming the great potential of bioactive compounds and are useful for the growth inhibition of the carcinogenic bacterium [86]. The beneficial soil organisms were exploited and the power of "biological resistance" in crops was reduced, making them more prone to pests and diseases [39]. Organic agriculture is an eco-friendly management system which upgrades agrological ecosystem health, biodiversity, and soil biological, physical, and chemical properties [87]. A number of organisms are associated with infection of leaves, flowers and fruit, resulting in tree decline and death. It has been reported that the fungal pathogens are more responsible for diseases [86]. In addition, there is still a need for developing lines or hybrids with larger fruits, small/ chicken-tongued seeds, and tolerance to pericarp splitting and have various maturity groupings [88]. Herbal medicines are now in great demand in the developing world for primary health care not because they are inexpensive but also for better cultural acceptability, better compatibility with the human body and minimal side effects [89].

\section{ACKNOWLEDGMENT}

The authors sincerely thank Shoolini University, Solan, Himachal Pradesh, for contributing to this study.

\section{CONTRIBUTION OF AUTHORS}

1. Gaurav Sharma: Compiled the literature sources, data analysis, and interpretation, wrote the manuscript

2. Nitika Thakur: Helped in data interpretation, the conceptualization of work, and its realization and manuscript evaluation.

\section{CONFLICTS OF INTEREST}

Nothing to declare.

\section{REFERENCES}

1. Sasikumar B. Genetic resources of curcuma: Diversity characterization and utilization. Plant Res 2005;3:230-51.

2. Wilson B, Abraham G, Manju VS, Mathew M, Vimala B, Sundaresan S, et al. Antimicrobial activity of Curcuma zedoaria and Curcuma malabarica tubers. J Ethnopharmacol 2005;99:147-51.

3. Nadkarni AK. Indian Materia Medica; Dr. KM Nadkarni's Indian Materia Medica: With Ayurvedic, Unani-Tibbi, Siddha, Allopathic, Homeopathic, Naturopathic and Home Remedies, Appendices and Indexes. Mumbai: Popular Prakashan; 1996.

4. Kumar U, Prajapati ND. Agro A Dictionary of Medicinal Plants. Jodhpur, India: Agrobios, Agrohouse; 2003. p. 216.

5. Kojima H, Yanai T, Toyota A. Essential oil constituents from Japanese and Indian Curcuma aromatica rhizomes. Plant Med 1998;64:380-1.

6. Gunduz S, Mozioğlu E, Yilmaz H. Biological activity of curcuminoids isolated from Curcuma longa. Rec Nat Prod 2008;2:24-94.

7. Deepa DA, Anita B, Sreelatha KT. Comparative study of the efficacy of curcumin and turmeric oil as chemo protective agents in oral submucous fibrosis: A clinical and histopathological evaluation. J Indian Acad Oral Med Radiol 2010;22:88-92.

8. Suhag A, Dixit J, Dhan P. Role of curcumin as a subgingival irrigant: A pilot study. Periodontal Pract Today 2007;2:115-21.

9. Ammon HP, Wahl MA. Pharmacology of Curcuma longa. Planta Med 1991;57:1-7.

10. Eigner D, Scholz D. Ferula assa-foetida and Curcuma longa in traditional medical treatment and diet in Nepal. J Ethnopharmacol 1999;67:1-6.

11. Parry JW. Spices. New York: Chemical Publishing Company; 1969.

12. Shankaracharya NB, Natarajan CP. Turmeric-chemistry, technology and uses. Indian Spices 1973;10:7-11.

13. Benzie IF, Wachtel-Galor S, editors. Herbal Medicine: Biomolecular and Clinical Aspects. Boca Raton, FL: CRC Press; 2011.

14. Kapoor LD. Handbook of Ayurvedic Medicinal Plants: Herbal Reference Library. Abingdon: Routledge; 2017.

15. Ruby AJ, Kuttan G, Babu KD, Rajasekharan KN, Kuttan R. Antitumour and antioxidant activity of natural curcuminoids. Cancer Lett 1995;94:79-83.

16. Priyadarsini KI. The chemistry of curcumin: From extraction to therapeutic agent. Molecules 2014;19:20091-112.

17. Vogel HA, Pelletier J. Curcumin-biological and medicinal properties. J Pharm 1815;2:24.

18. Roughley PJ, Whiting DA. Experiments in the biosynthesis of curcumin. J Chem Soc Perkin Trans 1973;1:2379-88.

19. Satoskar RR, Shah SJ, Shenoy SG. Evaluation of anti-inflammatory property of curcumin (diferuloyl methane) in patients with postoperative inflammation. Int J Clin Pharmacol Ther Toxicol 1986;24:651-4.

20. Kumar V, Lewis SA, Mutalik S, Shenoy DB, Venkatesh, Udupa N. Biodegradable microspheres of curcumin for treatment of inflammation. Indian J Physiol Pharmacol 2002;46:209-17.

21. Holder GM, Plummer JL, Ryan AJ. The metabolism and excretion of curcumin (1,7-bis-(4-hydroxy-3-methoxyphenyl)-1,6-heptadiene-3,5dione) in the rat. Xenobiotica 1978;8:761-8.

22. Sambaiah K, Ratankumar S, Kamanna VS, Satyanarayana MN, Rao MV. Influence of turmeric and curcumin on growth, blood constituents and serum enzymes in rats. J Food Sci Technol 1982;19:187-90.

23. Shankar TN, Shantha NV, Ramesh HP, Murthy IA, Murthy VS. Toxicity studies on turmeric (Curcuma longa): Acute toxicity studies in rats, guineapigs and monkeys. Indian J Exp Biol 1980;18:73-5.

24. Chainani-Wu N. Safety and anti-inflammatory activity of curcumin: A component of tumeric (Curcuma longa). J Altern Complement Med 2003;9:161-8

25. Aggarwal BB, Kumar A, Bharti AC. Anticancer potential of curcumin: Preclinical and clinical studies. Anticancer Res 2003;23:363-98.

26. Elgadir MA, Salama M, Adam AI. Anti-breast cancer from various natural sources-review. Int J Pharm Pharm Sci 2015;7:44-7.

27. Sajithlal GB, Chithra P, Chandrakasan G. Effect of curcumin on the advanced glycation and cross-linking of collagen in diabetic rats. Biochem Pharmacol 1998;56:1607-14.

28. Wilken R, Veena MS, Wang MB, Srivatsan ES. Curcumin: A review of anti-cancer properties and therapeutic activity in head and neck squamous cell carcinoma. Mol Cancer 2011;10:12.

29. Horie S. Chemoprevention of prostate cancer: Soy isoflavones and curcumin. Korean J Urol 2012;53:665-72.

30. Balakrishna A, Kumar MH. Evaluation of synergetic anticancer activity of berberine and curcumin on different models of A549, Hep-G2, MCF7, Jurkat, and K562 cell lines. Biomed Res Int 2015;2015:354614.

31. Sa G, Das T. Anti cancer effects of curcumin: Cycle of life and death. Cell Div 2008;3:14.

32. Ye MX, Li Y, Yin H, Zhang J. Curcumin: Updated molecular mechanisms and intervention targets in human lung cancer. Int $\mathrm{J}$ Mol Sci 2012;13:3959-78.

33. Shiri S, Alizadeh AM, Baradaran B, Farhanghi B, Shanehbandi D, Khodayari S, et al. Dendrosomal curcumin suppresses metastatic breast cancer in mice by changing $\mathrm{m} 1 / \mathrm{m} 2$ macrophage balance in the tumor microenvironment. Asian Pac J Cancer Prev 2015;16:3917-22.

34. Rajakrishnan V, Viswanathan P, Rajasekharan KN, Menon VP. Neuroprotective role of curcumin from Curcuma longa on ethanolinduced brain damage. Phytother Res 1999;13:571-4.

35. Ghoneim AI, Abdel-Naim AB, Khalifa AE, El-Denshary ES. Protective effects of curcumin against ischaemia/reperfusion insult in rat forebrain. Pharmacol Res 2002;46:273-9.

36. Nisar T, Iqbal M, Raza A, Safdar M, Iftikhar F, Waheed M. Turmeric: A promising spice for phytochemical and antimicrobial activities. Am Eur J Agric Environ Sci 2015;15:1278-88. 
37. Lidsky TI, Schneider JS. Lead neurotoxicity in children: Basic mechanisms and clinical correlates. Brain 2003;126:5-19.

38. Thakur N. Organic farming, food quality, and human health: A trisection of sustainability and a move from pesticides to eco-friendly biofertilizers. In: Probiotics in Agroecosystem. Singapore: Springer; 2017. p. 491-515.

39. Thakur N, Kashyap AS, Tripathi A. Impact of organic versus inorganic approaches on sustainable intensification and advance food security in tomato (cv. Solan lalima) under Mid-Hill Conditions of Himachal Pradesh. Berlin, Germany: Tropentag; 2015.

40. Menon VP, Sudheer AR. Antioxidant and anti-inflammatory properties of curcumin. In: The Molecular Targets and Therapeutic Uses of Curcumin in Health and Disease. Boston, MA: Springer; 2007. p. 105-25.

41. Jha AK, Verma VK, Deshmukh NA, Rymbai H, Assumi SR, Devi $\mathrm{MB}$, et al. Spices for Income Enhancement in NE Region: Needs and Focus. Training Manual on Entrepreneurship and Skill Development on Market Driven Production and Processing of High Value Crops of NEH Region. Lamphelpat: ICAR; 2017. p. 32.

42. Kulpapangkorn W, Mai-leang S. Effect of plant nutrition on turmeric production. Proc Eng 2012;32:166-71.

43. Herebian D, Choi JH, Abd El-Aty AM, Shim JH, Spiteller M. Metabolite analysis in Curcuma domestica using various GC-MS and LC-MS separation and detection techniques. Biomed Chromatogr 2009;23:951-65.

44. Gantait A, Barman T, Mukherjee PK. Validated method for estimation of curcumin in turmeric powder. Indian J Tradit Knowl 2011;10:247-50.

45. Roy S, Awasthi HI. Herbal medicines as neuroprotective agent: A mechanistic approach. Int J Pharm Pharm Sci 2017;9:1-7.

46. Jangle RD, Thorat BN. Reversed-phase high-performance liquid chromatography method for analysis of curcuminoids and curcuminoidloaded liposome formulation. Indian J Pharm Sci 2013;75:60-6.

47. Shu L, Cheung KL, Khor TO, Chen C, Kong AN. Phytochemicals: Cancer chemoprevention and suppression of tumor onset and metastasis. Cancer Metastasis Rev 2010;29:483-502.

48. Geethanjali A, Lalitha P, Firdhouse MJ. Analysis of curcumin content of turmeric samples from the various states of India. Indian J Pharm Chem Res 2016;2:55-62.

49. Ashraf K, Mujeeb M, Ahmad A, Ahmad N, Amir M. Determination of curcuminoids in Curcuma longa Linn. by UPLC/Q-TOF-MS: An application in turmeric cultivation. J Chromatogr Sci 2015;53:1346-52.

50. Horkey A. Rapid Analysis of Curcuminoids in Turmeric Extract Using the Agilent 1290 Infinity LC and STM Columns. USA: Agilent Technologies, Inc.; 2013

51. Kulkarni SJ, Maske KN, Budre MP, Mahajan RP. Extraction and purification of curcuminoids from Turmeric (Curcuma longa $\mathrm{L}$ ). Int $\mathrm{J}$ Pharmacol Pharm Technol 2012;1:81-4.

52. Popuri AK, Pagala B. Extraction of curcumin from turmeric roots. Int $\mathbf{J}$ Innov Res Stud 2013;2:289-99.

53. Garcia-Alloza M, Borrelli LA, Rozkalne A, Hyman BT, Bacskai BJ. Curcumin labels amyloid pathology in vivo, disrupts existing plaques, and partially restores distorted neurites in an Alzheimer mouse model. J Neurochem 2007;102:1095-104.

54. Sareen R, Nath K, Jain N, Dhar KL. Curcumin loaded microsponges for colon targeting ion inflammatory bowel disease: Fabrication, optimization, and in vitro and pharmacodynamics evaluation. J Biomed Biotechnol 2014;7:340701.

55. Ahmed T, Gilani AH. A comparative study of curcuminoids to measure their effect on inflammatory and apoptotic gene expression in an $A \beta$ plus ibotenic acid-infused rat model of Alzheimer's disease. Brain Res 2011;1400:1-18.

56. Ono K, Hasegawa K, Naiki H, Yamada M. Curcumin has potent antiamyloidogenic effects for Alzheimer's beta-amyloid fibrils in vitro. J Neurosci Res 2004; 75:742-50.

57. Naama JH, Al-Temimi AA. Al-Amiery AA. Study the anticancer activities of ethanolic curcumin extract. Afr J Pure Appl Chem 2010;4:68-73

58. Kim DS, Kim JY, Han Y. Curcuminoids in neurodegenerative diseases. Recent Pat CNS Drug Discov 2012;7:184-204

59. Maiti P, Manna J. Dietary curcumin: A potent natural polyphenol for neurodegenerative diseases therapy. MOJ Anat Physiol 2015;1:127-32.

60. Shehzad A, Ha T, Subhan F, Lee YS. New mechanisms and the antiinflammatory role of curcumin in obesity and obesity-related metabolic diseases. Eur J Nutr 2011;50:151-61.

61. Shishodia S, Singh T, Chaturvedi MM. Modulation of Transcription Factors by Curcumin. Berlin, Germany: Springer; 2007. p. 11-30

62. Surh YJ, Chun KS. Cancer Chemopreventive Effects of Curcumin.
Vol. 15. Berlin, Germany: Springer; 2007. p. 12.

63. Kuttan G, Kumar KB, Guruvayoorappan C, Kuttan R. Antitumor, Anti-invasive and Antimetastatic Effects of Curcumin. Vol. 13. Berlin, Germany: Springer; 2007. p. 16.

64. Agrawal DK, Mishra PK. Curcumin and its analogues: Potential anticancer agents. Med Res Rev 2010;30:818-60.

65. Kannappan R, Gupta SC, Kim JH, Reuter S, Aggarwal BB. Neuroprotection by spice-derived nutraceuticals: You are what you eat! Mol Neurobiol 2011;44:142-59.

66. Prasad S, Gupta SC, Tyagi AK, Aggarwal BB. Curcumin, a component of golden spice: From bedside to bench and back. Biotechnol Adv 2014:34:1053-64.

67. Bhandarkar SS, Arbiser JL. Curcumin as an Inhibitor of Angiogenesis. Berlin: Springer; 2007. p. 17-27.

68. Ravindran PN, Babu KN, Sivaraman K. Turmeric: The Genus Curcuma. Boca Raton: CRC Press; 2007.

69. Priyadarsini KI. The chemistry of curcumin: From extraction to therapeutic agent. Molecules 2014;19:20091-112.

70. Menon VP, Sudheer AR. Antioxidant and anti-inflammatory properties of curcumin. In: The Molecular Targets and Therapeutic Uses of Curcumin in Health and Disease. Boston: Springer; 2007. p. 105-125.

71. Ahn C, Obendorf SK. GC-MS analysis of dyes extracted from turmeric. Fiber Polym 2006;7:158-63.

72. Aggarwal BB, Sundaram C, Malani N, Ichikawa H. Curcumin: The Indian Solid Gold. Berlin: Springer; 2007. p. 12-37.

73. Karunagaran D, Joseph J, Kumar TR. Cell Growth Regulation. Vol. 12. Berlin: Springer; 2007. p. 54

74. Ramirez S, Bosca A, Soler A, Gutierrez MA. Antioxidant curcuma extracts decrease the blood lipid peroxide levels of human subjects. Age 1995;92:167-9

75. Kiso Y, Suzuki Y, Watanabe N, Oshima Y, Hikino H. Antihepatotoxic principles of Curcuma longa rhizomes. Planta Med 1983;49:185-7.

76. Waghmare PF, Chaudhari AU, Karhadkar VM, Jamkhande AS Comparative evaluation of turmeric and chlorhexidine gluconate mouthwash in prevention of plaque formation and gingivitis: A clinical and microbiological study. J Contemp Dent Pract 2011;12:221-4.

77. Miriyala S, Panchatcharam M, Rengarajulu P. Cardioprotective Effects of Curcumin. Vol. 15. Berlin: Springer; 2007. p. 29

78. Abu-Taweel GM, Ajarem JS, Ahmad M. Protective effect of curcumin on anxiety, learning behavior, neuromuscular activities, brain neurotransmitters and oxidative stress enzymes in cadmium intoxicated mice. J Behav Brain Sci 2013:3:74

79. Thakur N. Integrated approach for the management of differential patterns of diseases and pest incidence in lychee. In: Lychee Disease Management. Singapore: Springer; 2017. p. 265-77.

80. Khor TO, Huang Y, Wu TY, Shu L, Lee J, Kong AN. Pharmacodynamics of curcumin as DNA hypomethylation agent in restoring the expression of Nrf2 via promoter CpGs demethylation. Biochem Pharmacol 2011;82:1073-8.

81. Shu L, Khor TO, Lee JH, Boyanapalli SS, Huang Y, Wu TY, et al. Epigenetic $\mathrm{CpG}$ demethylation of the promoter and reactivation of the expression of Neurog 1 by curcumin in prostate LNCaP cells. AAPS J 2011;13:606-14

82. Thakur N, Thakur M, Thakur G, Lal S. Increased shelf life and safety of ketchup prepared from organically raised tomato (cv. Solan lalima). J Pure Appl Microbiol 2018;12:1351-4.

83. Thakur N. In silico modulation techniques for upgrading sustainability and competitiveness in agri-food sector. In: In Silico Approach for Sustainable Agriculture. Singapore: Springer; 2018. p. 161-7.

84. Thakur N. In silico modulation techniques for upgrading sustainability and competitiveness in agri-food Sector. In: In Silico Approach for Sustainable Agriculture. Singapore: Springer; 2018. p. 161-7.

85. Thakur N. Heat stability and antioxidant potential of beta-carotene isolated from a fungal isolate. Bulg J Agric Sci 2018;24:891-6.

86. Thakur N, Kumari J, Sharma M. Antimicrobial potential of herbal and chemical neonatal eye drops. Asian J Pharm Clin Res 2018;11:319-23.

87. Thakur N. Increased soil-microbial-eco-physiological interactions and microbial food safety in tomato under organic strategies. In: Probiotics and Plant Health. Singapore: Springer; 2017. p. 215-32.

88. Kashyap AS, Thakur N. Problems and prospects of lychee cultivation in India. In: Lychee Disease Management. Singapore: Springer; 2017. p. $139-66$

89. Kumar D, Sanghi A, Arora S, Chandra R, Thakur N. Individual and combined effects of extracts of leaves and bark of Tamarindus indica on in vitro membrane stabilizing and antioxidant activities. J Pharm Sci Res 2017;9:44 